\title{
The Role of Bridge Therapy Prior to Orthotopic Liver Transplantation
}

\author{
Meena A. Prasad, MD, and Laura M. Kulik, MD
}

\begin{abstract}
Orthotopic liver transplantation (OLT) offers the best chance for cure in the setting of unresectable hepatocellular carcinoma (HCC). A consensus statement recommends locoregional therapy (LRT) be considered in patients with HCC who are expected to wait more than 6 months for OLT to diminish dropout from the waiting list because of tumor progression. This article reviews LRT as a bridge to OLT in patients with HCC. ( $\mathrm{Natl}$ Compr Canc Netw 2014;12:1183-1191)
\end{abstract}

\section{NCCN: Continuing Education}

\section{Accreditation Statement}

This activity has been designated to meet the educational needs of physicians and nurses involved in the management of patients with cancer. There is no fee for this article. No commercial support was received for this article. The National Comprehensive Cancer Network (NCCN) is accredited by the ACCME to provide continuing medical education for physicians.
From the Department of Medicine, Division of Gastroenterology/ Hepatology, Northwestern University, Chicago, Illinois.

Submitted May 19, 2014; accepted for publication July 14, 2014.

The authors have disclosed that they have no financial interests, arrangements, affiliations, or commercial interests with the manufacturers of any products discussed in this article or their competitors.

Correspondence: Laura M. Kulik, MD, Department of Medicine, Division of Gastroenterology/Hepatology, Northwestern University, NMH/Arkes Family Pavilion, Suite 1900, 676 N Saint Clair, Chicago, Illinois 60611.

E-mail: Ikulik@nmff.org
NCCN designates this journal-based CME activity for a maximum of 1.0 AMA PRA Category 1 Credit(s) $^{\mathrm{TM}}$. Physicians should claim only the credit commensurate with the extent of their participation in the activity.

NCCN is accredited as a provider of continuing nursing education by the American Nurses Credentialing Center's Commission on Accreditation.

This activity is accredited for 1.0 contact hour. Accreditation as a provider refers to recognition of educational activities only; accredited status does not imply endorsement by NCCN or ANCC of any commercial products discussed/displayed in conjunction with the educational activity. Kristina M. Gregory, RN, MSN, OCN, is our nurse planner for this educational activity.

All clinicians completing this activity will be issued a certificate of participation. To participate in this journal CE activity: 1) review the learning objectives and author disclosures; 2 ) study the education content; 3) take the posttest with a $66 \%$ minimum passing score and complete the evaluation at http://education.nccn.org/ node/51010; and 4) view/print certificate.

Release date: August 8, 2014; Expiration date: August 8, 2015

\section{Learning Objectives}

Upon completion of this activity, participants will be able to:

- Describe the types of LRT that can be utilized as bridge therapy until liver transplant

- Discuss the existing study data on the impact of LRTmediated downstaging on patient outcomes

EDITOR

Kerrin M. Green, MA, Assistant Managing Editor, JNCCN—Journal of the National Comprehensive Cancer Network

Ms. Green has disclosed that she has no relevant financial relationships.

\section{CE AUTHORS}

Deborah J. Moonan, RN, BSN, Director, Continuing Education \& Grants Ms. Moonan has disclosed that she has no relevant financial relationships.

Ann Gianola, MA, Manager, Continuing Education \& Grants Ms. Gianola has disclosed that she has no relevant financial relationships. Kristina M. Gregory, RN, MSN, OCN, Vice President, Clinical Information Operations

Ms. Gregory has disclosed that she has no relevant financial relationships. 
Orthotopic liver transplantation (OLT) offers the best chance for cure in the setting of unresectable hepatocellular carcinoma (HCC). The Milan criteria (1 lesion $\leq 5 \mathrm{~cm}$ or 3 lesions all $\leq 3 \mathrm{~cm}$ without evidence of vascular invasion/metastasis) defined the upper limit of size/number of tumors that minimized the risk of posttransplant HCC recurrence. ${ }^{1}$ The United Network for Organ Sharing (UNOS) adopted these as the selection criteria for granting a prioritization on the waiting list. Patients meeting the Milan criteria are given a Model of End-Stage Liver Disease (MELD) score of 22 points that increases every 3 months in conjunction with repeat imaging confirming that the tumor burden has not exceeded the Milan criteria. No randomized controlled trials (RCTs) have addressed the role of locoregional therapy (LRT) before OLT. A consensus statement for OLT for HCC recommends that LRT be considered in patients expected to wait more than 6 months to diminish dropout from the waiting list because of tumor progression. ${ }^{2}$ Currently, no one form of LRT can be recommended over another. ${ }^{2}$ This article reviews LRT as a bridge to OLT in patients with HCC.

\section{Dropout}

The risk of dropout at 1 year has been estimated to be $15 \%$ to $30 \% .^{3}$ Factors associated with dropout include an $\alpha$-fetoprotein (AFP) level greater than 200 $\mathrm{ng} / \mathrm{mL}$, tumor size greater than $3 \mathrm{~cm}$ or multifocal disease, longer than 6 months' wait time, and lack of response to therapy. ${ }^{4-6}$ Patients with a single lesion greater than $3 \mathrm{~cm}$ or with 2 to 3 nodules have a reported cumulative dropout rate of $12 \%$ at 6 months and $56 \%$ at 12 months versus $0 \%$ at 6 months and $10 \%$ at 12 months in patients with a solitary lesion of $3 \mathrm{~cm}$ or less. ${ }^{4} \mathrm{~A}$ retrospective study by Cucchetti et $\mathrm{al}^{5}$ assessed the effectiveness of bridge therapy in preventing dropout and found that the $49 \%$ of candidates with a complete response to LRT had a significant reduction in dropout at 3, 6, and 12 months. Independent factors associated with dropout included higher MELD score, more advanced tumor stage at diagnosis, and lack of response to LRT. Given that LRT may decrease dropout through inhibiting tumor progression, a subset of patients with HCC may currently be overprioritized for OLT. ${ }^{6}$ Mehta et al ${ }^{7}$ showed that predictors of dropout or death included (1) 1 tumor of 3.1 to $5.0 \mathrm{~cm},(2)$ the presence of 2 to
3 tumors, (3) lack of a complete response to the first LRT, and (4) high AFP level ( $>20 \mathrm{ng} / \mathrm{mL}$ ) after the first LRT. ${ }^{7}$ These patients had 1- and 2-year dropout rates of $21.6 \%$ and $26.5 \%$, respectively, versus less than $2.0 \%$ at 1 and 2 years among patients with 1 tumor of 2 to $3 \mathrm{~cm}$, a complete response after the first LRT, and an AFP level of $20 \mathrm{ng} / \mathrm{mL}$ or less after the first LRT. Whether those with a solitary HCC responding to LRT will receive less prioritization in the future is unclear.

\section{Response to LRT and AFP Decline}

Response to LRT may provide insight into the biological behavior of tumors and serve as a selection criterion for OLT. Otto et $\mathrm{al}^{8}$ found that the lack of response to transarterial chemoembolization (TACE) was associated with posttransplant HCC recurrence regardless of Milan status. Other investigators have prioritized patients without evidence of response to LRT, regardless of tumor size/number, barring a lack of extrahepatic disease/vascular invasion or poorly differentiated HCC. Lack of response to LRT was an independent predictor of dropout regardless of tumor size. ${ }^{9}$ Additionally, although no significant difference was seen in post-OLT overall survival (OS), the risk of post-OLT HCC recurrence was significantly higher in patients without response to LRT ( $13 \%$ vs $2 \% ; P=.04)$. This suggests that OLT in those exceeding the Milan criteria should be restricted to those who demonstrate response to LRT to minimize the risk of post-OLT HCC recurrence.

Downstaging of AFP levels associated with LRT has been shown in various studies to have prognostic value in HCC. ${ }^{10}$ Patients with higher AFP levels before OLT, independent of tumor size or number, have had poorer outcomes post-OLT. ${ }^{11,12}$ Merani et $\mathrm{al}^{13}$ found that patients with AFP levels greater than $400 \mathrm{ng} / \mathrm{mL}$ at the time of listing had a significantly improved intention-to-treat (ITT) survival if the AFP level declined to less than $400 \mathrm{ng} / \mathrm{mL}$ before OLT compared with those whose levels did not decline. In fact, an AFP level of $400 \mathrm{ng} / \mathrm{mL}$ or less at the time of OLT was associated with an excellent 3-year OS rate post-OLT regardless of AFP at listing (78\% for those with an AFP $\leq 400 \mathrm{ng} / \mathrm{mL}$ at listing and $89 \%$ for those with an AFP $>400 \mathrm{ng} / \mathrm{mL}$ at listing), whereas an AFP level greater than $400 \mathrm{ng} / \mathrm{mL}$ at OLT was associated with a significantly lower OS (62\% for those with an 
AFP $\leq 400 \mathrm{ng} / \mathrm{mL}$ at listing and $54 \%$ for those with an AFP $>400 \mathrm{ng} / \mathrm{mL}$ at listing).

A prospective study divided AFP at the time of OLT into quartiles (up to $320 \mathrm{ng} / \mathrm{mL}$ ). AFP level at the time of OLT was an independent predictor of post-OLT OS, with increasing mortality as the AFP quartile increased..$^{14}$ In patients with AFP levels less than $15 \mathrm{ng} / \mathrm{mL}$, Milan criteria status did not impact OS; however, patients exceeding the University of California, San Francisco (UCSF) criteria had inferior OS despite an AFP level less than $15 \mathrm{ng} / \mathrm{mL}$ at the time of OLT. UCSF criteria is defined as either a solitary HCC measuring up to $6.5 \mathrm{~cm}$ in diameter or up to 3 lesions, each measuring less than $4.5 \mathrm{~cm}$ in diameter, with a total combined measurement of less than $8.0 \mathrm{~cm}$. A decline in AFP level associated with LRT was associated with no increase in postOLT mortality, but an increasing AFP level led to increased mortality. Taken in aggregate, these studies support the concept that AFP level at the time of OLT is an important determinant of post-OLT OS and should be considered in decisions regarding OLT candidacy in conjunction with radiographic findings.

\section{Downstaging}

The concept of downstaging refers to applying LRT to tumors outside of the Milan criteria to enable a surgical procedure that would otherwise be too risky or unfeasible, such as OLT or resection. The Milan criteria are used by UNOS to grant prioritization for OLT; however, some feel that the Milan criteria are too stringent and could be expanded without significantly compromising posttransplant results. Several publications have reported mostly single-center experiences with downstaging (Table 1). These reports are heterogeneous because of key issues, including the inclusion criteria of tumor size/number, AFP level, tumor grade, type of LRT used, criteria for response (ie, within Milan, degree of necrosis, decline in AFP/des$\gamma$-carboxyprothrombin level), and whether a mandated observation period is required to determine success of downstaging procedure (3 vs 6 months). LRT may lead to necrosis with evidence of lack of enhancement on imaging, without leading to a significant decrease in the size of the targeted lesion. The modified RECIST criteria has been endorsed as the measure to assess tumor response. ${ }^{15,16}$ The rate of reported successful downstaging ranges from $40 \%$ to $90 \%$ with LRT.
The UCSF group initially reported excellent 4-year OS rates of $92 \%$ in patients who underwent OLT after successful downstaging to the Milan criteria, with no HCC recurrence posttransplant after a median of 25 months. ${ }^{17}$ In an updated analysis of 122 patients entering a downstaging protocol, the authors found no significant difference among the 68 patients who were successfully downstaged and underwent OLT compared with those who were within the Milan criteria at the time of presentation (postOLT 5 -year OS rate: $80 \%$ vs $81 \% ; P=$ not significant [NS]; 5-year recurrence-free survival rate: $91 \%$ vs $88 \% ; P=\mathrm{NS}$, respectively). ${ }^{18}$ Additionally no significant difference was seen in outcomes between the groups in an ITT analysis. Pretreatment AFP levels greater than $1000 \mathrm{ng} / \mathrm{mL}$ and receipt of more than 3 LRT sessions predicted failure to achieve successful downstaging. These data support downstaging as a plausible option for a subset of patients exceeding the Milan criteria; however, OLT should probably be restricted to those with treatment response.

\section{Bridging Options for HCC}

Treatment for HCC depends on the degree of underlying liver dysfunction and tumor burden. Therefore, any therapy for HCC should be performed with the intent to minimize the risk of hepatic decompensation, despite the perception of OLT as a rescue therapy. The Barcelona Clinic Liver Cancer Staging classification (BCLC) takes into account tumor characteristics, liver function, and performance status, and pairs each stage with a recommended treatment modality; however, in clinical practice, adherence to the BCLC is not absolute and treatment decisions are individualized. ${ }^{2,19}$

\section{Ablative Therapy}

Percutaneous ethanol injection (PEI) was the original LRT first used in the 1980s to safely and effectively treat small HCC. PEI has largely been replaced by thermal ablation (radiofrequency and microwave ablation) because of the need for fewer treatment sessions, superior local tumor control, and higher $O S$ rates in meta-analyses. ${ }^{20,21}$ Electric current induces thermal injury with temperatures of $80^{\circ} \mathrm{C}$ to $100^{\circ} \mathrm{C}$, leading to coagulative necrosis. Radiofrequency ablation (RFA) can be performed via the percutaneous, laparoscopic, or thoracoscopic-transdiaphragmatic route, or through open laparotomy. 
Prasad and Kulik

Table 1 Single-Center Experiences With Downstaging

\begin{tabular}{|c|c|c|c|c|}
\hline Reference & Treatment & $\begin{array}{l}\text { Criteria for } \\
\text { Downstaging }\end{array}$ & Criteria for Response & Post-OLT Results \\
\hline $\begin{array}{l}\text { Graziadei et al, }{ }^{31} \\
2003\end{array}$ & TACE & $>$ UCSF downstaged & $>50 \%$ tumor reduction & 5-y OS, 25\% \\
\hline Otto et al, ${ }^{8} 2006$ & TACE & No upper size limit & RECIST & $\begin{array}{l}\text { 5-y RFS, } \\
93 \% \text { (stable) vs } 28 \% \\
\text { (minimal progression) }\end{array}$ \\
\hline Yao et al, ${ }^{17} 2008$ & $\begin{array}{l}\text { TACE, RFA, } \\
\text { PEI, combination } \\
\text { resection }\end{array}$ & $\begin{array}{l}1 \text { lesion }>5 \leq 8 \mathrm{~cm} \\
2 \text { or } 3 \text { lesions: at } \\
\text { least one }>3 \mathrm{~cm} \leq 5 \\
\mathrm{~cm}, T D \leq 8 \mathrm{~cm} \\
4 \text { or } 5 \text { lesions: all } \leq 3 \\
\mathrm{~cm}, \mathrm{TD} \leq 8 \mathrm{~cm}\end{array}$ & $\begin{array}{l}\text { Milan T2 or complete } \\
\text { tumor necrosis }\end{array}$ & $\begin{array}{l}\text { 4-y OS, } 94 \% \\
\text { No recurrence }\end{array}$ \\
\hline Ravaioli et al, ${ }^{49} 2008$ & $\begin{array}{l}\text { TACE, LR, } \\
\text { RFA, PEI }\end{array}$ & $\begin{array}{l}1 \text { lesion } \leq 8 \mathrm{~cm} \text {; } \\
5 \text { lesions, maximum } \\
\text { diameter } \leq 4 \mathrm{~cm} \text {, } \\
T D \leq 12 \mathrm{~cm}\end{array}$ & $\begin{array}{l}\text { Milan T2 (including } \\
\text { necrotic portion) } \\
\text { AFP } \leq 400 \mathrm{ng} / \mathrm{mL}\end{array}$ & 3-y DFS, 71\% \\
\hline $\begin{array}{l}\text { Chapman et al, } \\
2008\end{array}$ & TACE & UNOS stage III/IV & $\begin{array}{l}\text { Degree of necrosis/ } \\
\text { RECIST }\end{array}$ & $\begin{array}{l}5 \text {-y OS, } 94.1 \% \\
\text { Recurrence, } 6.0 \%\end{array}$ \\
\hline $\begin{array}{l}\text { Lewandowski et al, }{ }^{37} \\
2009\end{array}$ & $\begin{array}{l}\text { TACE } \\
\text { TARE }\end{array}$ & T3 & $\begin{array}{l}\text { Milan (entire lesion; } \\
\text { not just enhancement) }\end{array}$ & $\begin{array}{l}1-y \text { DFS, } 73 \% \\
1-y \text { DFS, } 89 \%\end{array}$ \\
\hline De Luna et al, ${ }^{50} 2009$ & TACE & >Milan & Milan & 3-y OS, 79\% \\
\hline Barakat et al, ${ }^{51} 2010$ & TACE + RFA or TARE & $\begin{array}{l}1 \text { lesion } \leq 6 \mathrm{~cm} \\
\leq 3 \text { lesions } \leq 4 \mathrm{~cm}\end{array}$ & Milan & $\begin{array}{l}\text { 2-y OS, } 75 \% \\
\text { Recurrence, } 14 \%\end{array}$ \\
\hline Jang et al,52 2010 & TACE & >Milan & Milan & $5-y$ DFS, $66 \%$ \\
\hline Toso et al, ${ }^{53} 2010$ & RFA, TACE TARE & $\begin{array}{l}\leq T T V \leq 250 \mathrm{~cm}^{3} \\
(1 \text { lesion } \leq 7.8 \mathrm{~cm} \text { or } \\
3 \text { lesions } \leq 5.4 \mathrm{~cm} \text { ) }\end{array}$ & $\begin{array}{l}\text { Milan criteria (inactive } \\
\text { nodules NOT counted) } \\
\text { AND AFP } \leq 400 \mathrm{ng} / \mathrm{mL}\end{array}$ & Pending \\
\hline
\end{tabular}

Abbreviations: AFP, $\alpha$-fetoprotein; DFS, disease-free survival; LR, liver resection; OLT, orthotopic liver transplantation; OS, overall survival; PEI, percutaneous ethanol injection; RFA, radiofrequency ablation; RFS, relapse-free survival; TACE, transarterial chemoembolization; TARE, transarterial radioembolization; TD, total diameter; TTV, total tumor volume; UNOS, United Network for Organ Sharing; UCSF, University of California, San Francisco.

Because percutaneous RFA can lead to incomplete tumor destruction in up to $20 \%$ of cases, it is crucial to perform overlapping zone partitioning and early follow-up imaging to investigate for viable tumor, and, if present, to repeat therapy or administer an additional form of LRT. Various considerations regarding tumor size, number, and location are required (Table 2). The size of the target lesion is the best predictor of complete necrosis: lesions less than 2.5 $\mathrm{cm}$ lead to complete necrosis in up to $90 \%$ of cases; however, lesions exceeding $5 \mathrm{~cm}$ result in complete necrosis in less than $50 \%$. In one study, RFA before OLT was an effective bridge to OLT in 15 of 23 transplant candidates, with a 3-year survival rate of $85 \% ; 2$ patients experienced disease recurrence but were noted to have microvascular invasion on ex- plant. ${ }^{22}$ Unfortunately, the dropout rate in this series was $21 \%$ over a mean waiting period of 7.9 months. No RCTs have evaluated RFA before OLT. However, several groups have described RFA before OLT. Mazzaferro et $\mathrm{a}^{23}$ prospectively treated 50 patients with HCC within the Milan criteria with a single session of RFA (percutaneous, laparoscopic, or open) and all patients were transplanted with a median waiting time of 9.5 months. A complete tumor response was found in $55 \%$ of explants ( $70 \%$ radiologic response). HCC recurrence was observed in $4 \%$ after a median follow-up of 22 months. Post-OLT OS was excellent, with 1 - and 3 -year OS rates of $95 \%$ and $85 \%$, respectively. A tumor size greater than $3 \mathrm{~cm}$ and time from treatment to OLT greater than 1 year were predictors of incomplete ablation with evidence of lo- 
Bridge Therapy to Orthotopic Liver Transplantation

cal recurrence. In another report, 52 patients listed for OLT, 10 of whom exceeded the Milan criteria, were treated with percutaneous RFA. ${ }^{24}$ After a mean waiting time of 12.7 months, 41 patients underwent OLT and $5.8 \%$ dropped out because of tumor progression; 1 - and 3-year survival rates post-OLT were $85 \%$ and $76 \%$, respectively, with no reported HCC recurrence. Finally, a retrospective cohort study of patients with HCC listed for OLT who received RFA versus no LRT found that those who received RFA had a longer wait time to OLT (9.5 vs 5.0 months). However, no significant difference was seen in dropout rate or post-OLT outcomes after controlling for waiting time. HCC characteristics, and not receipt of RFA, predicted patient outcome

\section{Transarterial Chemoembolization}

TACE is the most common treatment used to bridge patients to OLT. ${ }^{25}$ TACE involves the injection of chemotherapy - typically doxorubicin, cisplatin, and/ or mitomycin $\mathrm{C}$, emulsified in lipiodol, which serves as the delivery agent - into the hepatic artery supplying the targeted tumor, followed by particles to induce arterial stasis, leading to hypoxemia-induced tumor necrosis. ${ }^{26}$ Drug-eluting beads (DEB) provide an improvement over conventional TACE, with enhanced drug delivery to tumor, higher tumor retention of doxorubicin, and decreased systemic toxicity. ${ }^{27}$ The beads are embedded with doxorubicin and also serve as the embolizing agent. The other advantage of DEB is that they offer more of a standardization compared with conventional TACE; each vial of DEB contains 50 to $75 \mathrm{mg}$ of doxorubicin. For tumors within and exceeding the Milan criteria, 1 and 2 vials of DEB are recommended, respectively. ${ }^{28} \mathrm{~A}$ consensus statement has suggested that larger tumors should be treated with 2 treatment sessions. ${ }^{29}$ When comparing the extent of tumor necrosis in explanted livers, a retrospective analysis of 16 patients who underwent either bland embolization or TACE with DEB reported that complete necrosis occurred in $77.0 \%$ of lesions treated with TACE with DEB compared with $27.2 \%$ treated with bland embolization, showing a significantly better response with DEB. ${ }^{29}$ Another retrospective analysis of pre-OLT conventional TACE versus DEBTACE found a trend toward higher response rates, specifically a necrosis rate of $90 \%$ or greater $(44.7 \%$ vs $32.0 \% ; P=.2834)$, and a higher 3 -year recurrence-free survival in patients treated with DEB-TACE com-
Table 2 Factors to Consider Before RFA

\begin{tabular}{|c|c|}
\hline Size & Generally $<4 \mathrm{~cm}$ \\
\hline Number & $\leq 3$ \\
\hline \multirow[t]{4}{*}{ Location $^{a}$} & $\begin{array}{l}\text { Distant from major organs, bile ducts to } \\
\text { avoid injury }\end{array}$ \\
\hline & $\begin{array}{l}\text { Distant from large blood vessels to avoid } \\
\text { heat sink }\end{array}$ \\
\hline & $\begin{array}{l}\text { Subcapsular lesion can increase risk of } \\
\text { tumor seeding }\end{array}$ \\
\hline & Uncontrollable ascites can prohibit RFA \\
\hline
\end{tabular}

Abbreviation: RFA, radiofrequency ablation.

${ }^{a} A$ laparoscopic approach can be considered for lesions adjacent to other organs (eg, heart, colon, gallbladder, and stomach, or in locations such as the subcapsular, subdiaphragmatic regions).

pared with those treated with conventional TACE (87.4\% vs $61.5 \% ; P=.0493) .^{30}$

Unfortunately, more than $50 \%$ of patients undergoing TACE develop symptoms of postembolization syndrome, consisting of abdominal pain, fever, nausea, and vomiting. In patients with significant liver dysfunction (Child-Pugh class C) or compromised blood flow in the portal vein, such as from thrombosis, hepatofugal flow, or the presence of a transjugular intrahepatic portosystemic shunt, TACE can cause severe ischemic hepatitis.

In terms of TACE used as a bridging therapy, no prospective RCTs have confirming its efficacy in reducing dropout rates. Conflicting results have been published. Graziadei et al ${ }^{31}$ reported a 5-year ITT survival rate of $94 \%$ in 48 patients who received TACE as a bridging therapy before transplant, with a recurrence rate after transplant of $2.4 \%$. In contrast, Maddala et $\mathrm{al}^{32}$ reported a 5 -year survival rate of $61 \%$; however, only a minority of patients had HCC exceeding Milan criteria. Excellent post-OLT outcomes have been reported among patients treated with TACE who showed a radiographic response. ${ }^{8}$ In contrast, those experiencing minimal progression despite TACE had a significantly lower 5-year recurrence-free survival rate (28\% vs 93\%). ${ }^{8}$ Several studies have examined the ability of TACE to serve as a downstaging tool before transplant. $8,31,33,34$ When assessing response to therapy, the size of viable tumor (residual arterial enhancement) should be measured. Overall, the results, excluding those from early experience, have been encouraging.

Algorithms to determine suitability for repeat TACE were recently proposed. ${ }^{35}$ The hope is that these will aid in proper selection. 


\section{Transarterial Radioembolization}

Radioembolization is another form of intra-arterial therapy. Microspheres coated with yttrium-90 (Y90) are injected into the hepatic artery. Because of their small size $(25-30 \mathrm{mcg})$, they become preferentially trapped in the tumor capillary bed, allowing a high dose of Y90 radiation to be delivered to the tumor and rendering a greater tumoricidal effect while minimizing effects on the surrounding nontumorous tissue. ${ }^{36} \mathrm{~A}$ pretreatment staging angiogram is performed to determine whether coil embolization of aberrant vessels is required to prevent inadvertent delivery of microspheres to nontarget tissues. A technetium-99 macroaggregated albumin scan determines the degree of gastrointestinal and pulmonary shunting. The median time to see evidence of necrosis is 1.2 months, but the median time to see a decrease in size of the tumor is 6.6 months.

A particular area of interest with transarterial radioembolization (TARE) has been its role in downstaging HCC from T3 to T2 (to meet the Milan criteria). In a retrospective analysis, TARE was significantly more likely to lead to downstaging to T2 compared with TACE ( $58 \%$ vs $31 \% ; P=.023$ ). ${ }^{37}$ Furthermore, TARE was associated with a significant decrease in disease progression at 1 year compared with TACE $(15 \%$ vs $32 \% ; P<.05)$. Because waiting times for OLT have continued to increase despite the HCC MELD upgrade, this finding is of particular interest. However, because this study was not a headto-head comparison of TACE and TARE, additional studies are needed to confirm these results.

With the increasing clinical experience with TARE, unexpected observations have been made, including the concept of radiation segmentectomy ( $\leq 2$ segments). Excellent outcomes with a median OS of 53.4 months in solitary lesions less than 5 $\mathrm{cm}$ not amenable to RFA have been reported with TARE. These results also challenge the concept that lesions for which RFA is technically feasible may have similar results with TARE. ${ }^{38}$

No published RCT has compared $Y 90$ radiation with other LRT or systemic therapy. Retrospective analyses have found no significant difference in OS between TACE and TARE. ${ }^{39,40}$ TARE was associated with significantly shorter hospitalization, fewer treatment sessions, longer time to progression, and less abdominal pain, but a greater degree of fatigue. Quality of life was significantly better in TARE compared with TACE in prospective study. ${ }^{41}$ Ongoing RCTs, including STOP-HCC (ClinicalTrials. gov identifier: NCT01556490), are addressing the safety and efficacy of sorafenib with or without Y90 versus sorafenib alone.

\begin{tabular}{|c|c|c|c|}
\hline \multicolumn{4}{|c|}{ Kudo et al ${ }^{43}$ Study: Phase III, N=458 } \\
\hline & Sorafenib $b^{a}+T A C E$ & TACE & P Value \\
\hline Median TTP (mo) & 5.4 & 3.7 & .25 \\
\hline Median OS (mo) & 29.7 & $\begin{array}{l}\text { Not } \\
\text { reached }\end{array}$ & .79 \\
\hline \multicolumn{4}{|c|}{ Sansonno et $\mathrm{al}^{44}$ Study: Phase III, N-80, All HCV+ } \\
\hline & Sorafenib + TACE & TACE & $P$ Value \\
\hline Median TTP (mo) & 9.2 & 4.9 & $<.001$ \\
\hline Recurrance at $6 \mathrm{mo}$ & $22 \%$ & $77 \%$ & .005 \\
\hline \multicolumn{4}{|c|}{ SPACE ${ }^{54}:$ Phase II, N=307 } \\
\hline & Sorafenib ${ }^{b}+D E B$ & TACE & cP Value \\
\hline Median TTP $50 \%$ (d) & 169 & 166 & .072 \\
\hline Median TTP 25\% (d) & 112 & 88 & \\
\hline Median TTP $75 \%$ (d) & 285 & 224 & \\
\hline
\end{tabular}

Abbreviations: DEB, drug-eluting beads; HCV, hepatitis C virus; OS, overall survival; TACE, transarterial chemoembolization; TTP, time to progression.

aMedian sorafenib, $386 \mathrm{mg} / \mathrm{d}$.

${ }^{b}$ Median sorafenib, $566 \mathrm{mg} / \mathrm{d}$.

'One-sided log rank with alpha set at 0.15 
Bridge Therapy to Orthotopic Liver Transplantation

\section{Sorafenib}

Sorafenib, the only approved systemic therapy for HCC, has been shown to significantly improve OS in patients with Child-Pugh class A advanced disease compared with placebo. ${ }^{42}$ More recently, systemic therapy in combination with LRT was evaluated in patients with intermediate-stage HCC. The rationale for combining systemic therapy with LRT is to blunt the angiogenic surge associated with hypoxemia. To date, 3 RCTs have been conducted with mixed results (Table 3).43,44

Data on the use of sorafenib as a bridge to OLT are limited. A Markov model found sorafenib to be cost-effective compared with no therapy in patients with an anticipated wait time to OLT of less than 6 months. ${ }^{45}$ A pilot RCT ( $\left.n=20\right)$ of TARE-Y90 with or without sorafenib as a bridge to OLT in patients with HCC found that adding sorafenib did not augment radiologic or pathologic response to Y90 therapy. ${ }^{46}$ Findings also supported the data reported elsewhere of increased acute rejection and biliary complications within 30 days after OLT in patients taking sorafenib. ${ }^{47}$ This finding is in contrast to that of a retrospective analysis, which reported no increase in complications posttransplant but confirmed no difference in OS or HCC recurrence risk. ${ }^{48}$ Limited data support the role of combination therapy in the pretransplant setting.

\section{Conclusions}

Although prospective data comparing the efficacy of different forms of LRT are limited, LRT provides a safe and effective means to bridge patients with HCC to liver transplant. Furthermore, response to LRT may provide insight into the biological behavior of tumors and serve as a selection criterion for OLT. LRT can also successfully downstage tumors and allow for successful OLT. Currently, no one form of LRT can be recommended over another. Further prospective trials are needed.

\section{References}

1. Mazzaferro V, Regalia E, Doci R, et al. Liver transplantation for the treatment of small hepatocellular carcinomas in patients with cirrhosis. N Engl J Med 1996;334:693-699.

2. Clavien PA, Lesurtel M, Bossuyt PM, et al. Recommendations for liver transplantation for hepatocellular carcinoma: an international consensus conference report. Lancet Oncol 2012;13:e11-22.
3. Yao FY, Bass NM, Nikolai B, et al. Liver transplantation for hepatocellular carcinoma: analysis of survival according to the intention-to-treat principle and dropout from the waiting list. Liver Transpl 2002;8:873-883.

4. Yao FY, Bass NM, Nikolai B, et al. A follow-up analysis of the pattern and predictors of dropout from the waiting list for liver transplantation in patients with hepatocellular carcinoma: implications for the current organ allocation policy. Liver Transpl 2003;9:684-692.

5. Cucchetti A, Cescon M, Bigonzi E, et al. Priority of candidates with hepatocellular carcinoma awaiting liver transplantation can be reduced after successful bridge therapy. Liver Transpl 2011;17:13441354.

6. Maluf D, Fisher RA, Maroney T, et al. Non-resective ablation and liver transplantation in patients with cirrhosis and hepatocellular carcinoma (HCC): safety and efficacy. Am J Transplant 2003;3:312 317.

7. Mehta N, Dodge JL, Goel A, et al. Identification of liver transplant candidates with hepatocellular carcinoma and a very low dropout risk: implications for the current organ allocation policy. Liver Transpl 2013;19:1343-1353.

8. Otto G, Herber S, Heise $M$, et al. Response to transarterial chemoembolization as a biological selection criterion for liver transplantation in hepatocellular carcinoma. Liver Transpl 2006;12:1260-1267.

9. Vitale A, D'Amico F, Frigo AC, et al. Response to therapy as a criterion for awarding priority to patients with hepatocellular carcinoma awaiting liver transplantation. Ann Surg Oncol 2010;17:2290-2302.

10. Sala M, Fuster J, Llovet JM, et al. High pathological risk of recurrence after surgical resection for hepatocellular carcinoma: an indication for salvage liver transplantation. Liver Transpl 2004;10:1294-1300.

11. Mailey B, Artinyan A, Khalili J, et al. Evaluation of absolute serum alpha-fetoprotein levels in liver transplant for hepatocellular cancer. Arch Surg 2011;146:26-33.

12. Berry K, Ioannou GN. Serum alpha-fetoprotein level independently predicts posttransplant survival in patients with hepatocellular carcinoma. Liver Transpl 2013;19:634-645.

13. Merani S, Majno P, Kneteman NM, et al. The impact of waiting list alpha-fetoprotein changes on the outcome of liver transplant for hepatocellular carcinoma. J Hepatol 2011;55:814-819.

14. Lai Q, Avolio AW, Graziadei I, et al. Alpha-fetoprotein and modified response evaluation criteria in solid tumors progression after locoregional therapy as predictors of hepatocellular cancer recurrence and death after transplantation. Liver Transpl 2013;19:1108-1118.

15. Lencioni R, Llovet JM. Modified RECIST (mRECIST) assessment for hepatocellular carcinoma. Semin Liver Dis 2010;30:52-60.

16. Lencioni R. New data supporting modified RECIST (mRECIST) for Hepatocellular Carcinoma. Clin Cancer Res 2013;19:1312-1314.

17. Yao FY, Kerlan RK Jr, Hirose R, et al. Excellent outcome following down-staging of hepatocellular carcinoma prior to liver transplantation: an intention-to-treat analysis. Hepatology 2008;48:819-827.

18. Yao FY, Mehta N, Fix OK, et al. Down-stating of hepatocellular carcinoma to within Milan criteria prior to liver transplantation: comparison of long-term outcomes with tumors meeting Milan criteria without requiring down-staging [abstract]. Hepatology 2012;56(Suppl):211A. Abstract 40.

19. European Association For The Study of The Liver; European Organisation For Research and Treatment of Cancer. EASL-EORTC clinical practice guidelines: management of hepatocellular carcinoma. J Hepatol 2012;56:908-943.

20. Orlando A, Leandro G, Olivo M, et al. Radiofrequency thermal ablation vs. percutaneous ethanol injection for small hepatocellular 
Prasad and Kulik

carcinoma in cirrhosis: meta-analysis of randomized controlled trials. Am J Gastroenterol 2009;104:514-524.

21. Cho YK, Kim JK, Kim MY, et al. Systematic review of randomized trials for hepatocellular carcinoma treated with percutaneous ablation therapies. Hepatology 2009;49:453-459.

22. Fontana RJ, Hamidullah $\mathrm{H}$, Nghiem $\mathrm{H}$, et al. Percutaneous radiofrequency thermal ablation of hepatocellular carcinoma: a safe and effective bridge to liver transplantation. Liver Transpl 2002;8:1165-1174.

23. Mazzaferro V, Battiston C, Perrone S, et al. Radiofrequency ablation of small hepatocellular carcinoma in cirrhotic patients awaiting liver transplantation: a prospective study. Ann Surg 2004;240:900-909.

24. Lu DS, Yu NC, Raman SS, et al. Percutaneous radiofrequency ablation of hepatocellular carcinoma as a bridge to liver transplantation. Hepatology 2005;41:1130-1137.

25. Lubienski A. Hepatocellular carcinoma: interventional bridging to liver transplantation. Transplantation 2005;80:S113-119.

26. Schwartz M, Roayaie S, Uva P. Treatment of HCC in patients awaiting liver transplantation. Am J Transplant 2007;7:1875-1881.

27. Varela M, Real MI, Burrel M, et al. Chemoembolization of hepatocellular carcinoma with drug eluting beads: efficacy and doxorubicin pharmacokinetics. J Hepatol 2007;46:474-481.

28. Lencioni R, de Baere $\mathrm{T}$, Burrel $\mathrm{M}$, et al. Transcatheter treatment of hepatocellular carcinoma with Doxorubicin-loaded DC Bead (DEBDOX): technical recommendations. Cardiovasc Intervent Radiol 2012;35:980-985.

29. Nicolini A, Martinetti L, Crespi S, et al. Transarterial chemoembolization with epirubicin-eluting beads versus transarterial embolization before liver transplantation for hepatocellular carcinoma. J Vasc Interv Radiol 2010;21:327-332.

30. Nicolini D, Svegliati-Baroni G, Candelari R, et al. Doxorubicineluting bead vs conventional transcatheterarterial chemoembolization for hepatocellular carcinoma before liver transplantation. World J Gastroenterol 2013;19:5622-5632.

31. Graziadei IW, Sandmueller H, Waldenberger $\mathrm{P}$, et al. Chemoembolization followed by liver transplantation for hepatocellular carcinoma impedes tumor progression while on the waiting list and leads to excellent outcome. Liver Transpl 2003;9:557563.

32. Maddala YK, Stadheim L, Andrews JC, et al. Drop-out rates of patients with hepatocellular cancer listed for liver transplantation: outcome with chemoembolization. Liver Transpl 2004;10:449-455.

33. Chapman WC, Majella Doyle MB, Stuart JE, et al. Outcomes of neoadjuvant transarterial chemoembolization to downstage hepatocellular carcinoma before liver transplantation. Ann Surg 2008;248:617-625.

34. Majno PE, Adam $\mathrm{R}$, Bismuth $\mathrm{H}$, et al. Influence of preoperative transarterial lipiodol chemoembolization on resection and transplantation for hepatocellular carcinoma in patients with cirrhosis. Ann Surg 1997;226:688-701; discussion 701-683.

35. Hucke F, Sieghart W, Pinter M, et al. The ART-strategy: sequential assessment of the ART score predicts outcome of patients with hepatocellular carcinoma re-treated with TACE. J Hepatol 2014;60:118-126.

36. Kulik LM, Mulcahy MF, Omary RA, Salem R. Emerging approaches in hepatocellular carcinoma. J Clin Gastroenterol 2007;41:839-854.

37. Lewandowski RJ, Kulik LM, Riaz A, et al. A comparative analysis of transarterial downstaging for hepatocellular carcinoma: chemoembolization versus radioembolization. Am J Transplant 2009;9:1920-1928.
38. Vouche M, Habib A, Ward TJ, et al. Unresectable solitary HCC not amenable to RFA: Multicenter radiology-pathology correlation and survival of radiation segmentectomy. Hepatology 2014;60:192-201.

39. Salem R, Lewandowski RJ, Kulik L, et al. Radioembolization results in longer time-to-progression and reduced toxicity compared with chemoembolization in patients with hepatocellular carcinoma. Gastroenterology 2011;140:497-507 e492.

40. Moreno-Luna LE, Yang JD, Sanchez W, et al. Efficacy and safety of transarterial radioembolization versus chemoembolization in patients with hepatocellular carcinoma. Cardiovasc Intervent Radiol 2013;36:714-723.

41. Salem R, Gilbertsen $M$, Butt $Z$, et al. Increased quality of life among hepatocellular carcinoma patients treated with radioembolization, compared with chemoembolization. Clin Gastroenterol Hepatol 2013;11:1358-1365 e1351.

42. Llovet JM, Ricci S, Mazzaferro V, et al. Sorafenib in advanced hepatocellular carcinoma. N Engl J Med 2008;359:378-390.

43. Kudo M, Imanaka K, Chida N, et al. Phase III study of sorafenib after transarterial chemoembolisation in Japanese and Korean patients with unresectable hepatocellular carcinoma. Eur J Cancer 2011;47:2117-2127.

44. Sansonno D, Lauletta G, Russi S, et al. Transarterial chemoembolization plus sorafenib: a sequential therapeutic scheme for HCV-related intermediate-stage hepatocellular carcinoma: a randomized clinical trial. Oncologist 2012;17:359-366.

45. Vitale A, Volk ML, Pastorelli D, et al. Use of sorafenib in patients with hepatocellular carcinoma before liver transplantation: a costbenefit analysis while awaiting data on sorafenib safety. Hepatology 2010;51:165-173.

46. Vouche M, Kulik L, Atassi R, et al. Radiological-pathological analysis of WHO, RECIST, EASL, mRECIST and DWI: Imaging analysis from a prospective randomized trial of $Y 90+/$ - sorafenib. Hepatology 2013;58:1655-1666

47. Truesdale AE, Caldwell SH, Shah NL, et al. Sorafenib therapy for hepatocellular carcinoma prior to liver transplant is associated with increased complications after transplant. Transpl Int 2011;24:991998.

48. Frenette CT, Boktour M, Burroughs SG, et al. Pre-transplant utilization of sorafenib is not associated with increased complications after liver transplantation. Transpl Int 2013;26:734-739.

49. Ravaioli M, Grazi GL, Piscaglia F, et al. Liver transplantation for hepatocellular carcinoma: results of down-staging in patients initially outside the Milan selection criteria. Am J Transplant 2008;8:25472557.

50. De Luna W, Sze DY, Ahmed A, et al. Transarterial chemoinfusion for hepatocellular carcinoma as downstaging therapy and a bridge toward liver transplantation. Am J Transplant 2009;9:1158-1168.

51. Barakat O, Wood RP, Ozaki CF, et al. Morphological features of advanced hepatocellular carcinoma as a predictor of downstaging and liver transplantation: an intention-to-treat analysis. Liver Transpl 2010;16:289-299.

52. Jang JW, You CR, Kim CW, et al. Benefit of downsizing hepatocellular carcinoma in a liver transplant population. Aliment Pharmacol Ther 2010;31:415-423.

53. Toso C, Mentha G, Kneteman NM, et al. The place of downstaging for hepatocellular carcinoma. J Hepatol 2010;52:930-936. 
Bridge Therapy to Orthotopic Liver Transplantation

\section{Instructions for Completion}

To participate in this journal CE activity: 1) review the learning objectives and author disclosures; 2 ) study the education content; 3) take the posttest with a $66 \%$ minimum passing score and complete the evaluation at http://education.nccn.org/ node/51010; and 4) view/print certificate. After reading the article, you should be able to answer the following multiple- choice questions. Credit cannot be obtained for tests completed on paper. You must be a registered user on NCCN.org. If you are not registered on NCCN.org, click on "New Member? Sign up here" link on the left hand side of the Web site to register. Only one answer is correct for each question. Once you successfully answer all posttest questions you will be able to view and/or print your certificate. Software requirements: Internet

\section{Posttest Questions}

1. True or False: Prospective data shows that radioembolization is superior to chemoembolization for downstaging patients with HCC who are awaiting transplantation.

2. Which of the following factors is NOT associated with dropout?
a. AFP levels
b. Tumor size
c. Lack of response to LRT

d. None of the above

3. The concept of refers to applying LRT to tumors outside of the Milan Criteria to enable a surgical procedure that would otherwise be too risky or unfeasible, such as OLT or resection.
a. Dropout
b. Bridge therapy
c. Downstaging

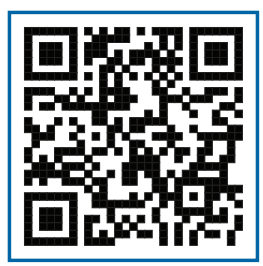

